$\Phi=\Phi$

\title{
Development of the conceptual framework for a quality improvement training programme for health professionals in the ministry of health and social services in Namibia
}

\author{
Julia Paul Nangombe ${ }^{1 *}$, Amukugo Hans Justus ${ }^{2}$ \\ ${ }^{1}$ Quality Assurances and Quality Improvement. Office of Vice President, Veterans Affairs, Republic of Namibia \\ ${ }^{2}$ Lecturers, School of Nursing and School of Public health, Faculty of health Sciences University of Namibia \\ *Corresponding author E-mail: julianangombe@yahoo.com
}

\begin{abstract}
This article describe the process followed by the researcher in the development of the conceptual framework for a quality improvement training programme for health professionals in the Ministry of Health and Social Services in Namibia. The conceptual framework of this study was based on the Practice Orientated Theory of Dickoff (1968) that assisted with explaining the concepts used in developing the quality improvement training programme for health professionals at the health facilities. Dickoff' s (1968) practice orientated theory consists of the agent, recipients, context, procedure, dynamics, and the terminus. In this study, the agent was a quality specialist, the recipients were health professionals, the context was the health facilities, the dynamics were challenges that health professionals were experiencing; the procedure was the training programme, while the terminus was knowledgeable and skillful health professionals in quality health care delivery.
\end{abstract}

Keywords: Development; Conceptual Framework; Quality Improvement; Training Programme; Health Professionals.

\section{Introduction}

Miles and Huberman (1994) in Maxwell (2004) define a conceptual framework "...[as] visual or written product, one that explains, either graphically or [in] narrative form the main things to be studied - the key factors, concepts, or variables - and the presumed relationships among them". The conceptual framework in this study was based on identified concepts of schematics or graphics to express ideas or explain a theory and to make inferences or draw conclusions. Zimabrdo, Mcdermott, Jansz, and Metaal (1995) explain that schemas direct people's thinking and interpretation of things around them. An educational programme is viewed necessary to stimulate and refresh cognitive thinking and an understanding of QI and QA at health care facilities. Alejandro, Humberto, and Agustin (2005) define a cognitive map (CM) as "....a structure of concepts of a specific domain that are related through causeeffect relations with the aim to simulate behavior of dynamic systems". The writers emphasise that a CM is "...mental constructed ideas to illustrate a model or explain the reasoning of a conceptual framework through graphical mental model that externalizes as a person understands, believes and organizes a subject of analysis" (Alejandro, Humberto, \& Agustin, 2007). A reasoning map by Dickhoff, James and Wiedenbach (1968) in Mothiba (2012) was adopted in developing an educational programme to facilitate quality health care delivery at the health care facilities.

In this study, the hierarchical representation of the reasoning map consisted of the following components: Agent (specialist), recipients (health professionals), context (health care facilities), dynamics, procedures, and terminus (station/position). Each component consisted of elements that were part of the study findings, which assisted with developing a Quality Improvement Educational Programme for Health (QIEPH) to empower health professionals with knowledge, skills and abilities to facilitate quality health care delivery.

The practice orientated theory of Dickoff (1968) in Mothiba (2012) consists of five components that apply to the development of the training programme components for health care facilities to. The theory consists of the agent, recipients, context, dynamics, and terminus for the programme activities. The practice orientated theory by Dickoff (1968) was used to mould the concepts into logical reasoning to develop a quality improvement training programme for health professionals at health care facilities of the MoHSS.

\section{Aim And Objectives}

The aim is to develop a conceptual framework as basis for the development of a training programme for health professionals that facilitate quality health care and services delivery at the health care facilities.

The objectives of this are

\section{Methodology}

A self-administered checklist was completed by 21 top managers while five FGDs consisting of eight participants and 12 individual interviews were conducted in four regions. The SPSS software 
program was used to analyse the checklist responses. All FGDs and individual interview were voice recorded and transcribed verbatim. The transcripts and field notes were transcribed manually and analyzed using Tech's method for qualitative data analysis with the purpose of coding and developing themes. After data reduction and merging, five main themes emerged. The findings from checklist, individual interviews and FGDs will be a basis for phase 2 .

In this Phase 2 of the study that describes the conceptual framework and logical approach to developing the QI educational programme for the health care facilities in the MoHSS

\section{Findings}

The conceptual framework of this study was based on the practice orientated theory of Dickhoff (1968), which explain concepts and analyse the prescribed activities that are aimed at realizing the programme goals, namely:
- Who or what perform activities (agent)?

- Who or what is the recipient of the activity?

- In what context is the activity performed?

- What is the guiding procedure technique of protocol of the activity?

- What are energy sources for the activity?

- What is the end product of the activity?

The hierarchical representation of the reasoning map consisted of the following components: Agent (specialist), recipients (health professionals), context (health care facilities), dynamics, procedures, and terminus (station/position). Each component consisted of elements that were part of the study findings, which assisted with developing a Quality Improvement Educational Programme for Health (QIEPH) to empower health professionals with knowledge, skills and abilities to facilitate quality health care delivery.

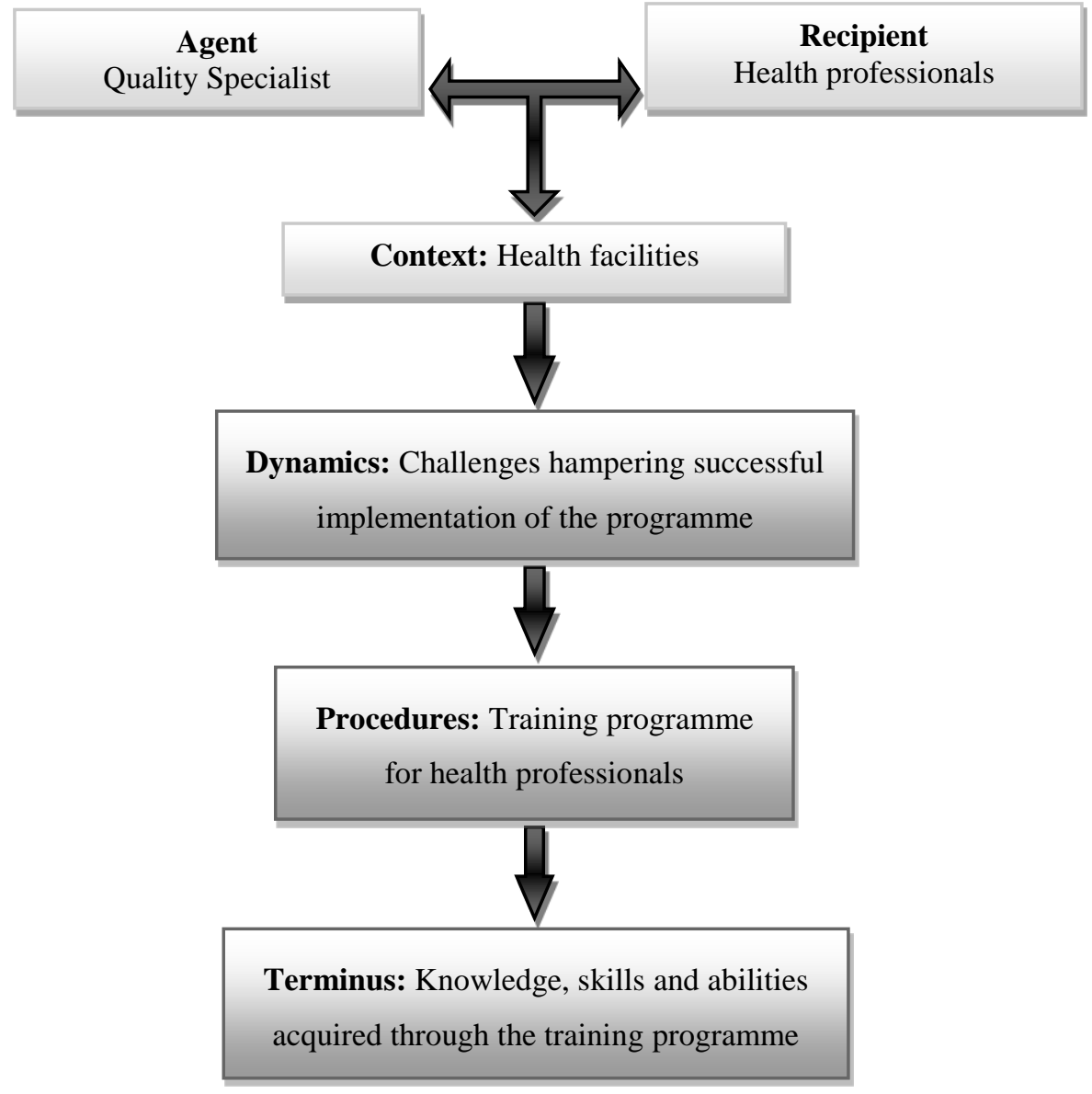

Fig. 1: Reasoning Map.

Figure 1 presents the elements or activities adapted from Dickhoff' s practice orientated theory (1986) to describe the conceptual framework and the process of developing a quality improvement educational programme for health professionals. Dickhoff (1986) uses the same components to develop a theory. Those components were adapted in the above reasoning map

The characteristic for six elements such as the agent, recipients, context, dynamics, and terminus for the programme activities are described as follow: .

\section{Agent}

The agent in this study referred to the researcher who facilitated the implementation of a quality improvement training programme for health professionals at health care facilities of the MoHSS. The agent is the main focal person responsible for planning, coordinating, and developing a programme (Dickoff et al. 1968). 


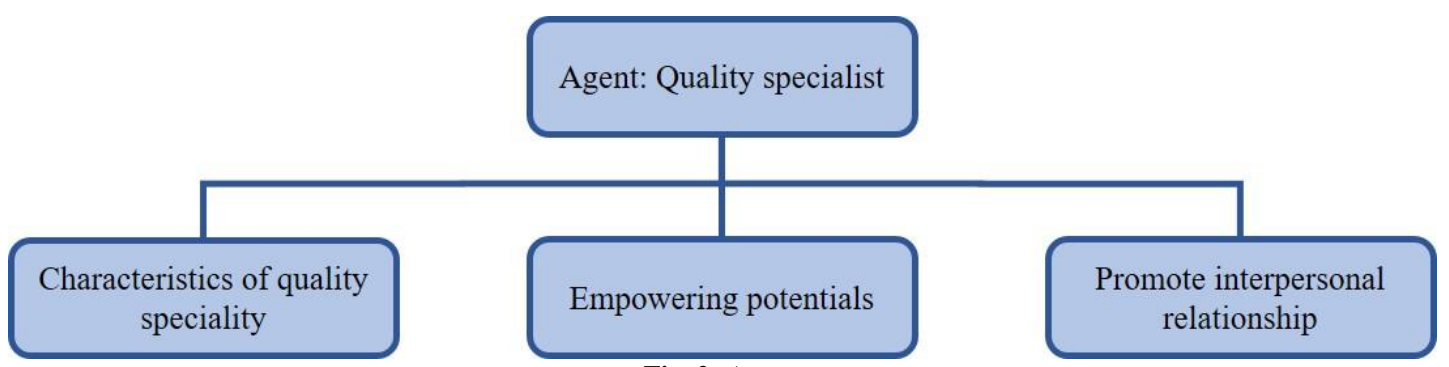

Fig. 2: Agent.

Figure 2 indicates the characteristics and abilities of the agent to empower potential and promote roles and responsibilities while facilitating the implementation of the quality educational programme at the health facilities. The characteristics, abilities to empower, and the promotion of interpersonal are described in more detail.

Characteristics and roles of the agent

The agent should be able to design, plan, implement, monitor, and evaluate a quality improvement educational programme. The agent should be hard-working, committed, and passionate about quality improvement, assertive, inventive, approachable, honest, trustworthy, self-motivated, energetic, attentive, knowledgeable, and proficient to handle the situations in relation to quality in health care. The agent has to be a good mediator and mentor.

Empowering potential

Empowerment is one of the activities the agent should perform with the view of enhancing knowledge, skills, and abilities to enable recipients to address the challenges that are hampering quality health care delivery at the health care facilities. To provide a sustainable QI and QI programme, recipients need to be empowered in order to become experts in quality management with the capacity to work independently, as well as to generate and analyse in formation for planning and decision making purposes at the health care facilities. Experience indicated that health professionals often felt unsupported and unprepared to respond effectively to emerging and re-emerging occurrences of illness and diseases. With insufficient support, they found themselves in situations where it was not possible for them to provide optimum results. Thus, the agent would provide clear support to assist the recipients with creating a favourable work environment for learning that focuses on patient care.
Promotion of interpersonal relationships

Effective interpersonal relationships would facilitate the successful implementation of the programme. One of the roles of the agent is to ensure that interpersonal relationships become a tool for successful implementation of the educational programme by creating new ways of communicating and assisting the establishment of good relationships. The agent should have insight in personality characteristics to change attitudes with the view of cultivating a spirit of continual professional development and active participation in the programme. The programme requires continual engagement and exchange of information among different stakeholders (internal and external) and interpersonal relationships to build a healthy working environment. In order to eliminate frustrations due to poor interpersonal relationships and ineffective communication, the agent should develop guidelines to establish strong interpersonal relationships.

\section{Recipients}

The recipients in this study were health professionals who would benefit from participating in the training programme by receiving knowledge, skills, and abilities to improve quality health care delivery at the health care facilities. Dickoff et al. (1968) describe the second activity as the recipient. In this study, the recipients were health professionals from different categories (doctors, nurses, pharmacists, social workers, environmental health officers, and hospital managers) at the health care facilities in the MoHSS who had the responsibility to effectively and efficiently provide quality health care.

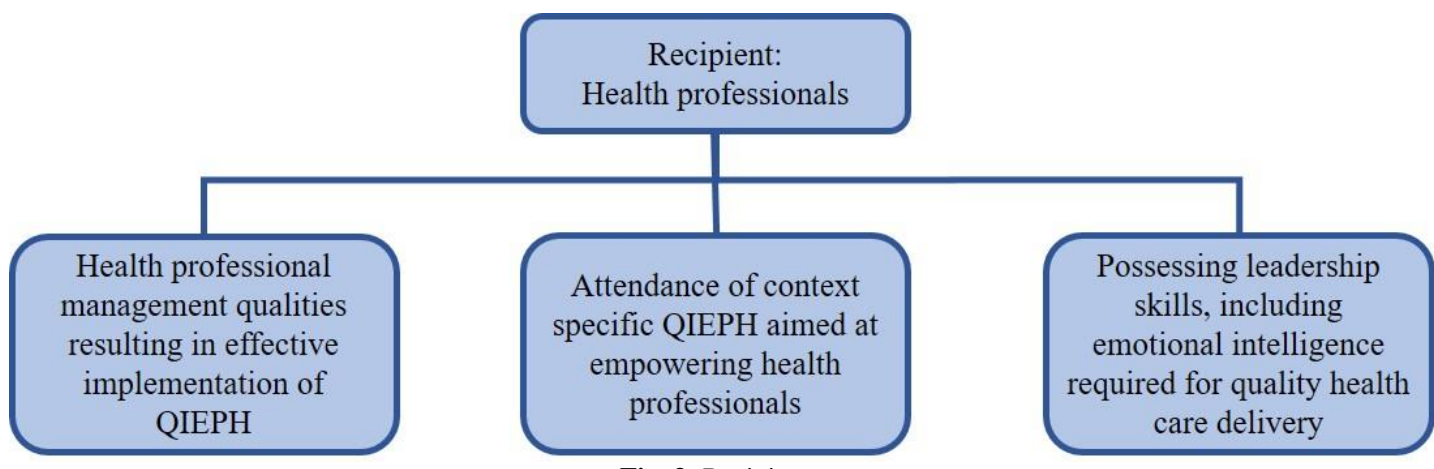

Fig. 3: Recipients.

Figure 3 illustrates the recipient as the beneficiary of the quality education programme (QIEPH). Health professionals were expected to participate in the quality improvement educational programme to improve their knowledge, skills, and abilities (KSAs) with the view of enabling them to deliver quality patient care. In order to understand the gaps in the existing and needed KSAs, job roles would be clearly defined according to their job descriptions at the Human Resource Management Division.

Health professional management qualities:

The challenging programme is designed to equip recipients at health care facility level with relevant knowledge, skills, abilities, and attitudes to manage QI and QA activities effectively. Specific managerial competencies could be acquired through the training programme, which is designed to empower health professionals on QI and QA at the health care facilities.

Attendance of context specific QIEPH aimed at empowering health professionals:

Attending the QIEPH would empower recipients to change attitudes towards patient safety, create a favourable environment, and promote a positive culture that focuses on change management. The QIEPH was informed by recipients' experiences in the health care facility context. It was expected to promote ownership, effective interpersonal relationships, and motivational strategies to improve quality at the health care facilities. Attending the training programme would enhance knowledge, skills, and abilities to enable the recipients to perform a number of activities; such as gath- 
ering and evaluating clinical data from different health care facilities, analysing data to determine patterns and trends in quality health care delivery, and utilising relevant tools, e.g. performing a root cause analysis to map specific patient care trends.

Tenure of leadership skills:

Conger, Spreitzer and Lawler (1999) state that a successful programme of QI requires determined and committed leadership with skills and abilities to advance a theory of change and translate it into practice by following a number steps. The leadership in this programme had to influence and motivate health professionals to accept change, develop mechanisms to facilitate the implementation of the training programme, as well as provide coaching and mentorship tutorials to encourage health professionals to participate actively in the training programme. The top management should possess relevant leadership qualities to manage a QA and QI programme at the health care facilities. UNESCO (1997) describes some leadership qualities required for programme development; such as good experience, competent professional with relevant training, ability to inspire confidence, support to encourage staff, promotion of teamwork and partnerships, creating a positive and conducive working environment, vision, as well as planning and decision making skills. In short, leadership should have competencies in all management aspects; such as strategic planning, organising, research and information management to facilitate the implementation of the QI programme at the health care facilities.

\section{Context}

The context is the health care facilities that are providing health care and services to the patients and clients in the MoHSS. The specific context in this programme was the referral, intermediate, and district hospitals operating under the MoHSS. The third aspect of the practice orientated theory described by Dickoff et al. (1968), as indicated in Mothiba (2012) is the context. The programme was designed for the health care facilities; specifically, for referral, intermediate and district hospitals under the MoHSS. Figure 4illustrates the context in which the programme would be implemented.

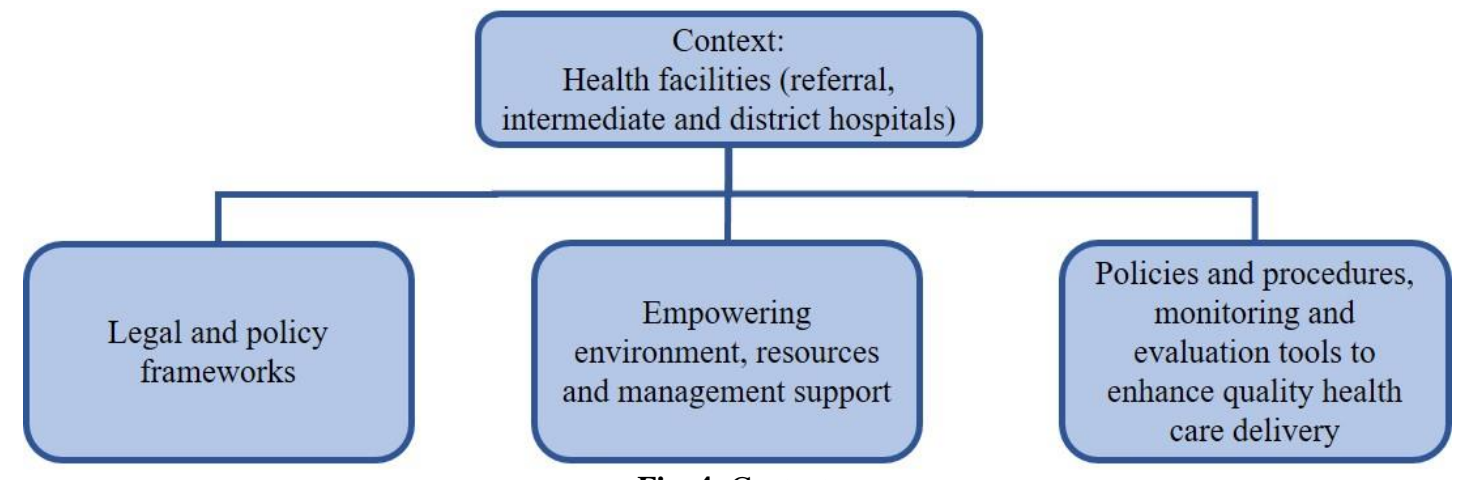

Fig. 4: Context.

Figure 4 illustrates the context that consists of legal frameworks, an empowering environment with resources and management support, as well as policies and procedures that include the monitoring and evaluation of the QI educational programme.

It is important to understand the context of health care facilities in relation to the genealogy of the MoHSS policy framework and existing approaches of QA and QI to facilitate a quality improvement educational programme at the health care facilities. Health care facilities fall under the mandate of the MoHSS, which operates under the legal framework of the Namibian Government. In empowering health professionals, it is crucial to understand the policies that shape the day-to-day activities at the health care facilities. The link between the legal frameworks, as well as the health context policies and procedures needs to be established with the view of supporting health professionals to improve quality health care delivery.

Characteristics of the health care facilities

Health care facilities consist of large hospitals that are providing specialised services, as well as medium and small establishments and structures with different abilities to provide quality health care to the clients. Health care facilities provide care and services at different levels with different inputs and resources at their disposal. In the MoHSS, health care facilities are categorised according to a specific level of care and service delivery.

The MoHSS head office (National Directorates) is responsible for planning, coordination, and administration. The Windhoek Central Hospital (WCH) is a tertiary-level hospital that offers highly specialised staff and technical equipment; such as cardiology, intensive care, and specialised imaging units. Clinical services are highly differentiated by function and it serves as a teaching hospital with a bed capacity of between 700 and 900 beds.

The intermediate hospitals at Katutura, Oshakati, and Rundu provide unique services with none or few specialties that focus mainly on internal medicine, obstetrics, gynaecology, paediatrics, general surgery, and general practice. Limited laboratory services are available for general but not for specialised pathological analysis. All specialised cases are referred to $\mathrm{WCH}$ for treatment.

District hospitals, primary health care facilities, and outreach services (health centres and clinics) focus on prevention, promotion, and rehabilitation.

Health care facilities face different challenges that stifle quality health care delivery; such as inadequately trained personnel, inability to provide the needed care and services, and unavailability of specialised services. To improve the accessibility of care and services, referral systems need to be simplified to meet health care needs at any level of health care. In order to address the challenges narrated in Chapter 3, certain aspects need to be adopted to assist health care facilities improve the situation of quality health care delivery.

\section{a) Effective management of resources}

Effective management of resources is one of the important elements to enhance quality health care delivery, since no health care facility would function effectively without adequate resources; such as human, material, and financial resources to procure medical equipment and pay salaries of employees. The participants indicated that health care facilities faced challenges on this continuum due to inadequate infrastructure, shortage of human resources, and unequal allocation and distribution of resources, which resulted in poor provision of health care and service delivery.

Facilitate an understanding of policies and guidelines

The capacity of health professionals to understand the standards and processes would facilitate effective implementation of policies and guidelines. Facilitating an understanding of polices is one of the essential elements that points at the KSAs of health professionals and management to enhance quality health care. Quality is knowledge driven; without anyone to facilitate an understanding of policies and guidelines, the implementation would be ineffective. That was evident from the health professionals' discussion that there was a lack of common understanding and no sufficient 
support to facilitate the implementation of a QI and QA policy to improve quality health care delivery.

Effective interpersonal relationships

Effective interpersonal relationships are the outcome of good communication, "...[i]s the most important aspect of the service delivery as, communication with patients is vital to delivering service satisfaction because when hospital staff takes the time to answer questions of concern to patients, it can alleviate many feelings of uncertainty" (Dutton, Starbuck, \& Krippendorff, 2002). Besides, health professionals are in constant interaction with patients, management, and professional bodies to share information about treatment and care of patients, hence these characteristics need to be enhanced.

\section{Facilitate research and information management}

Research and information are the core elements of QI, since it relies on constant data. For a health care facility to ensure quality assurance standards and improvement of processes of care and services, health professionals need to be empowered with the view of enabling them to generate and analyse data for quality improvement. Although there was strong agreement on the management responses that health care facilities were conducting research, opportunities still exist to improve skills and competencies on this continuum.

Empowering environment with resources and management support

The findings of the study indicated discrepancies and weaknesses of inadequate resources and low interest from management to provide full support to empower health care facilities to enhance quality health care delivery. An empowering environment at health care facilities can be related to a "learning organisation" that supports the development of capacity, strengthens the confidence of health professionals to take initiative in quality improvement health care delivery activities. "Learning organizations are organizations where people continually expand their capacity to create the results they truly desire, where new and expansive patterns of thinking are nurtured, where collective aspiration is set free, and where people are continually learning to see the whole together" (Senge, 2001).

\section{Dynamics}

The dynamics in this study were the challenges that the health professionals were experiencing in terms of obstructions or interferences with the provision of health care services (Chapter 3 ). In order to improve quality health care delivery, there was a need to improve the skills, competencies, and attitudes of those health care workers who were providing health care and services to support the successful implementation of the programme.

Dynamics were based on the storylines shared by the health professionals as forming the source of energy. If outstanding factors as the source of energy are not managed well, it might hinder the successful implementation of quality health care delivery at the health care facilities. The fourth aspect described by Dickoff et al.'s (1968) practice theory in Mothiba (2012) is the dynamics (energy source of the activity) (Figure 4.5).

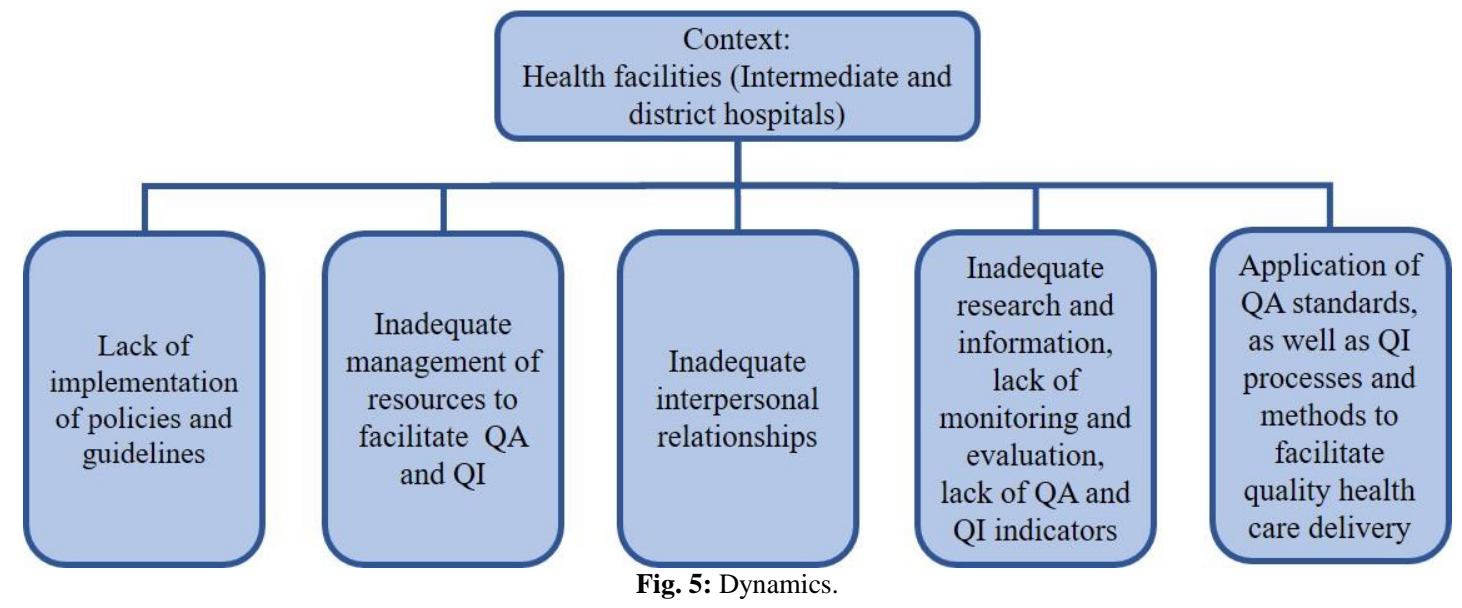

Figure 5 illustrates the challenges experienced in providing QI and QA, the proposed strategies to cope with these challenges, as well as the involvement and requirements for successful implementation of the QIEPH. Participants indicated some factors that hindered quality health care delivery.

Lack of implementation of available policies and guidelines Participants indicated the reasons for ineffective implementation that comprised certain factors: Inadequate organisational structure for QI and QA, an insufficient or lack of a common understanding of QI and QA policies and guidelines to facilitate quality adherence, as well as a lack of measurement indicators for monitoring and evaluating quality activities to facilitate quality health care delivery.

Inadequate management of resources to facilitate QI and QA

Experiences of inadequacies and deficiencies in management of resources was translated into poor or lack of supportive supervision, ambiguity in defining roles and responsibilities of managing quality health care, inadequate management of resources, absence of retention strategies for health professionals, a shortage in human resources, inadequate infrastructure (equipment and material resources to meet patient demands), long waiting times, unbearable workloads, as well as an unequal allocation of financial resources.

Influence of inadequate interpersonal relationships on QI and QA
In most cases, health professionals stated that poor communication and interpersonal relationships among health workers, supervisors (managers), and patients resulted in negative attitudes, a lack of motivation or low morale, and at times resistance to change, since goals or intentions were not properly communicated. Hence, often team were neither well-functioning nor encouraged to improve the quality of health care.

Inadequate research and information, and lack of monitoring and evaluating QI and QA indicators

Inadequate research and information, and lack of monitoring and evaluating QI and QA indicators were highlighted as some of the causes of poor quality health care outcomes. Despite positive responses by top management that health care facilities were conducting research, health professionals shared that they did not have sufficient skills to apply scientific methods of analysis, and to present professional data for planning and decision making purposes. At health care facilities where research was intensively carried out, there was a difficulty to actively monitor and evaluate the steps of health care delivery. The strategies and methods to manage obstructions, as well as the ethics and requirements for successful implementation of the programme had to be described. Application of QA and QI process standards to facilitate quality health care delivery

Health professionals would be enabled and empowered to apply QA and QI standards and methods to improve quality health care 
delivery. The study described specific tools that would be essential to assist health professionals with addressing the challenges to quality health care delivery at the health care facilities. Some of the tools were identified; for example, the cause-effect analysis, fishbone, as well as qualitative and quantitative methods of research. The tools were used to gauge patient satisfaction with the health care and service delivery.

Strategies to cope with factors that may obstruct the effectiveness of the QIEPH

The agent (researcher) had already developed strategies through this study that would empower health professionals and facilitate a smooth process of implementing the quality improvement programme in the MoHSS. The study proposed a number of strategies to assist health professionals to deal with the challenges that obstructed quality health care delivery. Firstly, the study exposed the challenges that were hampering quality health care delivery. Secondly, the educational programme would empower health professionals to improve their knowledge, skills, and abilities to competently handle those challenges in a more professional manner. Thirdly, health professionals were provided with two sets of guidelines to understand the implementation and evaluation process of the quality improvement programme in the MoHSS. The goals of the programme formed part of the strategies to facilitate the smooth implementation that should be adopted by all the stakeholders.

Values clarification of everybody involved in the QIEPH management

The values clarification in this programme sought to create a common goal and understanding of the purpose of QI and QA in the MoHSS. The values of the MoHSS and those of the QI programme needed to be clarified, since there might be a different understanding among health professionals, hospital managers (recipients), and stakeholders (patients, communities, and organisations). These values should be unambiguously clarified to avoid them from becoming stumbling blocks to the implementation of the programme. Clarification of values of people involved in the QIEPH was necessary to determine the standards that guided the process of implementing the programme. In order to minimise conflict in this process, it would be important to abide by the goals of the programme, since its development was based on the experiences at health care facilities and the principles of quality improvement and assurance in the ministry.

Prerequisites for an effective QIEPH

The requirements for health professionals to attend the training programme would be guided by the training policy of the MoHSS and the identified training needs of health professionals at a particular health care facility to address the challenges that were hampering quality health care delivery. The prerequisite for attending the training programme would also be derived from the identified gaps in competencies, skills, and abilities by the critical problems pertaining to provision of quality health care at the health care facilities. Furthermore, the criteria for attending the training programme would be defined in accordance with the identified areas at each health care facility and in accordance with the training guidelines of the MoHSS.

\section{Procedure}

Procedures are referred as processes that are employed to address certain problems or guide the actions to implement a policy or programme. In this study, the procedure was the training programme that was implemented at the health care facilities to empower health professionals with knowledge, skills, and abilities to facilitate quality health care delivery. The procedure (programme) explains the development, implementation, evaluation techniques, programme content, learning objectives, and learning outcomes (Figure 6)

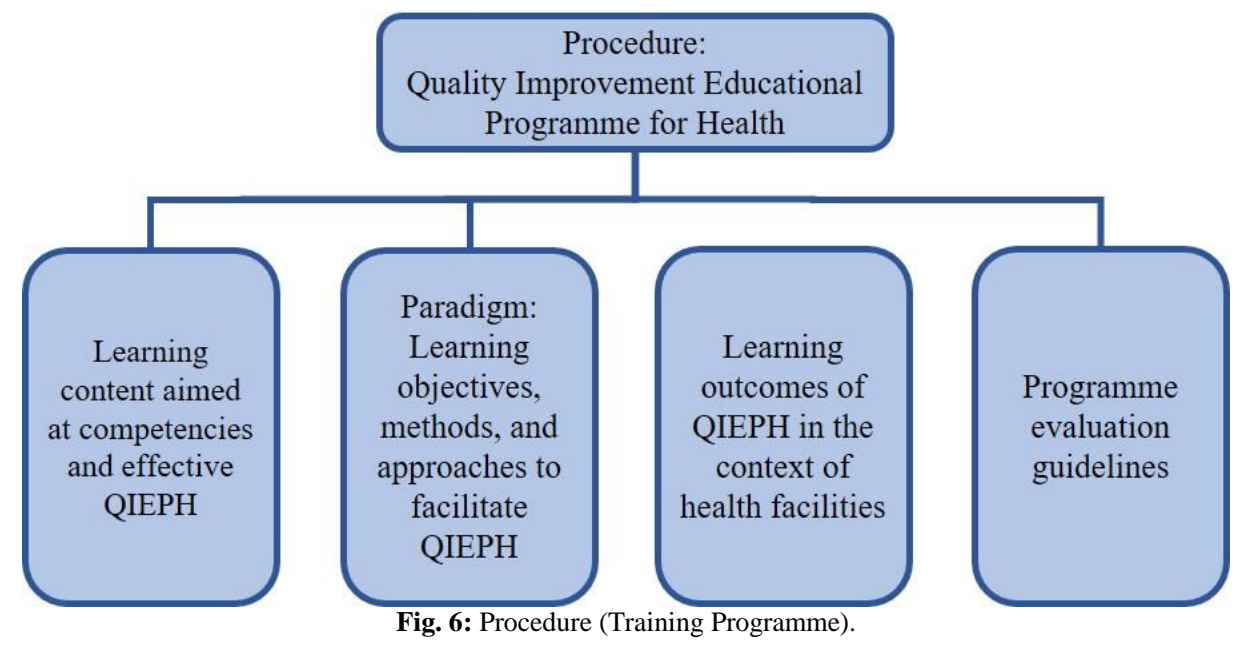

Figure 6 illustrates the components of the procedure (programme), which are the learning content aimed at developing competencies, the paradigm of learning methods and approaches to facilitate the programme, guidelines for the implementation of the programme a health care facility context, and the evaluation guidelines of the programme.

The content of the training programme was derived from five main themes, 17 sub-themes and the conceptual framework based on the situation analysis about challenges faced by the health care facilities. The five themes were:

- Lack of implementation of policies and guidelines;

- Inadequate resources;

- Lack of interpersonal relationships;

- Inadequate understanding of quality assurance and quality improvement; and

- Inadequate research to provide evidence-based information during treatment and patient care.

The structure or programme design was based on the five thematic areas in this section, these areas are briefly discussed.

Policies and guidelines

The content of the programme should focus on developing competencies for successful implementation of QA and QI policies and guidelines, on enhancing the organisational structure with correctly defined roles and responsibilities and supervision mechanisms, as well as on implementing measures or indicators for QA and QI standards and processes that enhance quality health care delivery. Resources to facilitate quality health care delivery

Health professionals should be empowered to develop strategies that address the challenges of shortage and poor management of human resources, inadequate infrastructure, unequal allocation of resources, long waiting times, and unbearable workloads. Interpersonal relationships among health professionals 
Programme content was developed to improve attitudes among staff members and towards patients, develop effective communication, introduce strategies and mechanisms to encourage a positive culture, team work, and to assist health professionals with dealing with change at the health care facilities.

Research and information on QA and QI

Research is the heart of QA and QI. Given the description of new developments of information and technology in medicine, the objectives of a quality improvement training programme might not be fully achieved. The programme content should empower health professionals with research methods and tools to investigate and analyse the relationships, causes of variations, and deviations in quality health care delivery. Health professionals were, therefore, required to demonstrate the acquired competencies after participating in the programme; hence the terminus was the last activity of the conceptual framework of the programme.

Application of QA and QI standards and methods to facilitate quality health care delivery
The quality training programme wishes to empower health professionals to apply the knowledge in practice based on an understanding of the concepts, standards, and methods of QA and QI. Health professionals need to be empowered to apply the most recent methods and standards of QA and QI to improve health care delivery and patient care. In addressing the challenges of an inadequate understanding of QA and QI, the content of the programme focused on the tools and methods to enhance equitable health care delivery.

\section{Terminus}

In this study, the word terminus referred to the endpoint of the training programme, which completed the activities in the cycle of developing the conceptual framework of the training programme, as described by Dickoff et al.'s (1968) practice theory in Mothiba, (2012) that the terminus is the last or final activity of the process.

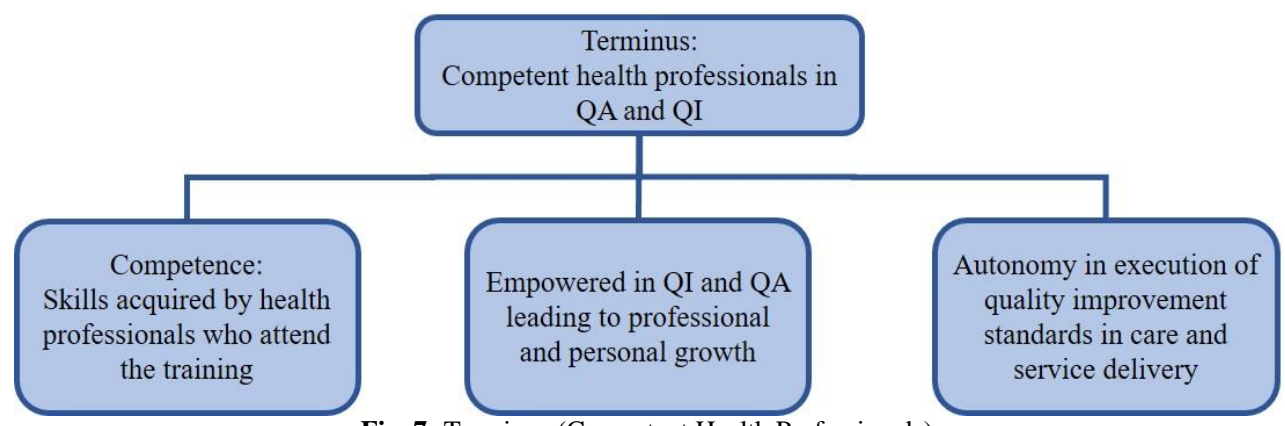

Fig. 7: Terminus (Competent Health Professionals).

Figure 7 illustrates the final activity of Dickoff's (1968) practice orientated theory, since the terminus completes the training programme process. This activity described how health professionals demonstrated the abilities to apply QA and QI concepts and methods during execution of their duties that resulted in improved quality health care delivery.

The training programme was developed based on several theories, such as the theories of Dickoff (1968), and Van Meyer, Kolb and Deming. The guidelines of evaluating the training programme are described as follow.

Competencies of health professionals in QA and QI

The health professionals' experiences of quality health care delivery indicated a lack of certain competencies in relation to QA and QI, which were identified as obstacles to quality health care delivery. In order to address the challenges and gaps experienced in quality health care delivery, health professionals needed to be equipped with technical competencies in relation to the expected changes in providing quality health care.

Among the competencies required to address deficiencies in quality health care delivery was the empowerment of management to unlock the potential of resources; including strategic planning, coordinating, mobilising, acquisition and utilisation. The study had already indicated the challenges of inadequate resources due to mismanagement and misallocation. That required developing a system with clear guidelines for administration, recording, information retrieval, implementation, monitoring and evaluation, feedback, as well as progress reporting to ensure the successful end-point activity of this process (Lieb, 1991).

QI and QA empowerment lead to professional and personal growth

Empowerment in QA and QI would be achieved by successful participation in the phases of the implementation and evaluation of the training programme, as well as after successful completion of training in line with the objectives of the training programme. The training programme had clear expectations and deliverables (results) for attending the programme.

- Involvement in the evaluation process of the guidelines for the implementation of the quality improvement training programme to determine its viability and the implementation process at the health care facilities.

- Familiarisation with the training approach that was presented to the MoHSS top management and hospital managers for approval, rollout, and implementation of the programme at the health care facilities.

- Actively participated in defining the change improvement processes to be used at the health care facilities, including identifying the appropriate mechanisms for implementation, approval steps followed, feedback, as well as reporting about the quality improvement and quality assurance processes.

- The working group was responsible for the development of the programme modules and competencies inventory to be approved and submitted for certification in consultation by NQA and HPCNA with stakeholders to ensure the extensive implementation of the programme at the MoHSS, health care facilities, and training institutions in the country.

Involvement in developing the terms of reference for the Quality Assurance and Continual. Improvement Working Group, as a representative of the MoHSS and stakeholders was identified to work on the training programme.

Autonomy in the execution of quality improvement standards for care and service delivery

Autonomy in this study refers to the execution of QI activities to enhance quality health care delivery at all levels of health care and to ensure that health care services are accessible and responsive to the health care needs and demands of the clients. In this view, each level of health care should have identified roles and responsibilities to ensure the successful implementation of the quality improvement training programme. Autonomy would enable health care facilities to make decisions on issues affecting their performance instead of waiting for the national level to decide on their behalf. This study revealed that the improvement of quality patient care depended on health professionals with authority on certain levels on the basis of decentralised functions, roles, and responsibilities. The findings indicated that quality health care delivery would be optimised when certain functions, such as medical specialist positions, were transferred to the district hospitals with the 
view of enabling timely provision of health care services. In order for health care facilities to execute quality improvement activities to the best of their ability, they should be empowered to be selfsufficient to respond promptly to patient needs. It was revealed that health care facilities were failing not because they had inadequate skills but as a result of a lack of power and authority to make decisions on their own, since they were too reliant on the national level decisions. The agent in consultation with the top management would facilitate the process to transfer power of certain functions from the national level to enable effective and efficient implementation of the quality improvement programme.

\section{Conclusion}

The conceptual framework based on the six factors of the practice orientated theory by Dickoff that was adapted to develop a learning activity for the health professionals in the MoHSS. These factors helped to organise the concepts into understandable components, which was necessary for the development and implementation of the training programme. The six factors of the practice orientated theory by Dickoff (1968) in Mothiba (2012) discuss the roles of the agent, recipients, context, procedure, dynamics, and terminus, which were adapted to suit the health care facilities context in the MoHSS. These factors should respond to the goals and objectives to facilitate the implementation process of this programme

\section{References}

[1] Miles, M. B. \& Huberman, A. M. (1994). Qualitative data analysis: an expanded sourcebook, ( ${ }^{\text {nd }}$ ed.). California: Sage.

[2] Maxwell, J. A. (2004). Chapter three. Conceptual Framework. What Do You Think Is Going On? Retrieved October, 13 from http://www.sagepub.com/upm-data/5056_Maxwell_Chapter_3.pdf.

[3] Zimbardo, P. (2007). Encyclopedia of Mental Health: Shyness. The shyness Clinic Stanford University: California.

[4] Alejandro, P., Humberto, S. \& Agustin, G. (2007). Cognitive Maps: An Overview and their Application for Student Modeling. National Polytechnic Institute. Vol. 10(3). Retrieved October 17, 2014 from http://www.scielo.org.mx/pdf/cys/v10n3/v10n3a4.pdf.

[5] Mothiba, T. M. (2012). A Training Programme for Cost Centre Management with a Dual Role at a Tertiary Hospital Complex in the Limpopo Province. PhD Thesis. University of Johannesburg. $\begin{array}{llll}\text { Retrieved October } & 3, & 2014 & \text { from }\end{array}$ http://content.healthaffairs.org/content/22/2/103.full.html.

[6] Conger, J. A, Spreitzer, G. M. \& Lawler, E. E. III, (1999). (Eds.) The Leader's Change Handbook. An Essential Guide to Setting Direction \& Taking Action. Jossey-Bass. A Wiley Company. San Francisco.

[7] U. S. Department of Health and Human Services (2011). Developing and Implementing a QI Plan. Health Resources and Services Administration. Retrieved June, 12, 2012 from http://www.nap.edu/catalog/10027.htm.

[8] United Nations Education Social Coordination (1997). Guidance and Counselling Programme Development, Module 8. Botswana. $\begin{array}{llll}\text { Retrieved November } & 2, & 2014 & \text { from }\end{array}$ $\mathrm{http} / /$ :www.unesco.org/education/mebam/module.

[9] Senge, P. (2001). The engine for facilitators. The fifth discipline field book. Master Facilitator Journal. Retrieved March, 15, 2014, from http://www.masterfacilitator.com/daialogue.html.

[10] Mothiba, T. M. (2012). A Training Programme for Cost Centre Management with a Dual Role at a Tertiary Hospital Complex in the Limpopo Province. PhD Thesis. 461 University of Johannesburg. Retrieved October 3, 2014 from http://content.healthaffairs.org/content/22/2/103.full.html .

[11] Kolb, A. \& Kolb D. A. (2001). Experiential Learning Theory Bibliography. Boston, MA: McBer and Co. Retrieved 23, 2014 from http://trgmcber.haygroup.com/Products/learningbibliography.htm.

[12] Kolb, D. A. (1984). Experiential Learning. Englewood Cliffs, NJ: Prentice Hall.

[13] Lieb, S. (1991). Principles of adult learning, Phoenix, AZ: Vision South Mountain Community College. Retrieved September 24, 2014 from http://honolulu.hawaii.edu/intranet/committees/. 